\title{
Editorial
}

\section{New trends and potential applications of photocatalysis for better environment}

EDITOR'S NOTE. Responding to the fast-changing and rapidly expanding interdisciplinary character of the field of photochemistry and related subjects of applied and environmental importance and the needs of the readership, the Intern J. Photoenergy starting from this issue will publish proceedings of international conferences.

This special issue of the Intern J. Photoenergy on New Trends and Potential Applications of Photocatalysis for Better Environment brings together reviewed papers presented at the $8^{\text {th }}$ Japan/Korea Symposium on Catalysis held at Osaka Prefecture University in May 2001. The topics covered by the many papers are of importance in photocatalysis, solar chemistry and environmental photochemistry.

Special thanks are due to Masakazu Anpo for editing the manuscripts for publication.

Prof. M. S. A. Abdel-Mottaleb Founding Managing Editor

FORWARD. In recent years, new, environmentally friendly photocatalytic sciences and technologies-that is, photocatalysis for the recovery and protection of a clean and safe environment-has been acknowledged to be one of the most vital areas of scientific research. These include such systems as efficient degradation of toxic organic materials in water and elimination of $\mathrm{NO}_{x}$ in air.

This special issue of Intern J. Photoenergy contains a collection of the highlight contributions of the Japan/Korea Symposium on Catalysis, the first to be held in the $21^{\text {st }}$ Century, at Osaka Prefecture University in May 2001. The participants to this symposium from academia and industry were able to address and discuss the most advanced approaches, developments and important breakthroughs in these fields.

We would like to thank each contributor to this issue as well as each participant to this symposium, whose great efforts have made this a most successful and memorable event, not only towards the advancement of research but for the strengthening of the close ties between our two countries. We hope that the work we do today will-one day play an important role in making this world a better place for all.

Prof. Masakazu Anpo Guest Editor

Osaka Prefecture University, Japan Chairman of the $8^{\text {th }}$ Japan/Korea Symposium on Catalysis 


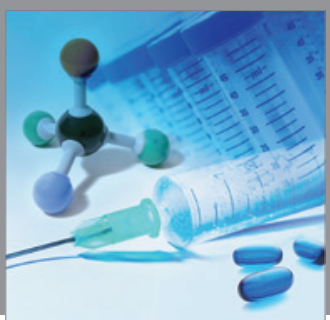

International Journal of

Medicinal Chemistry

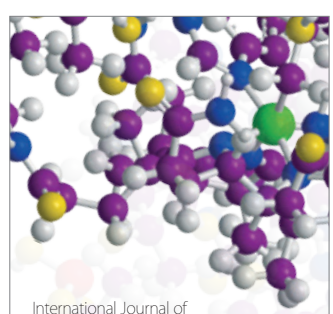

Carbohydrate Chemistry

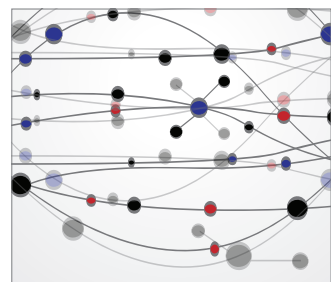

The Scientific World Journal
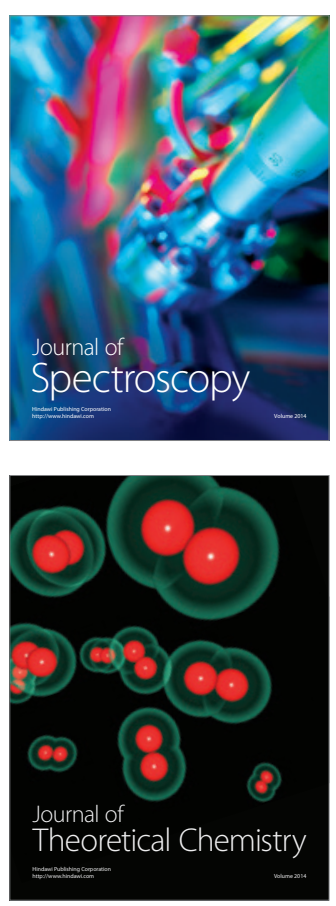
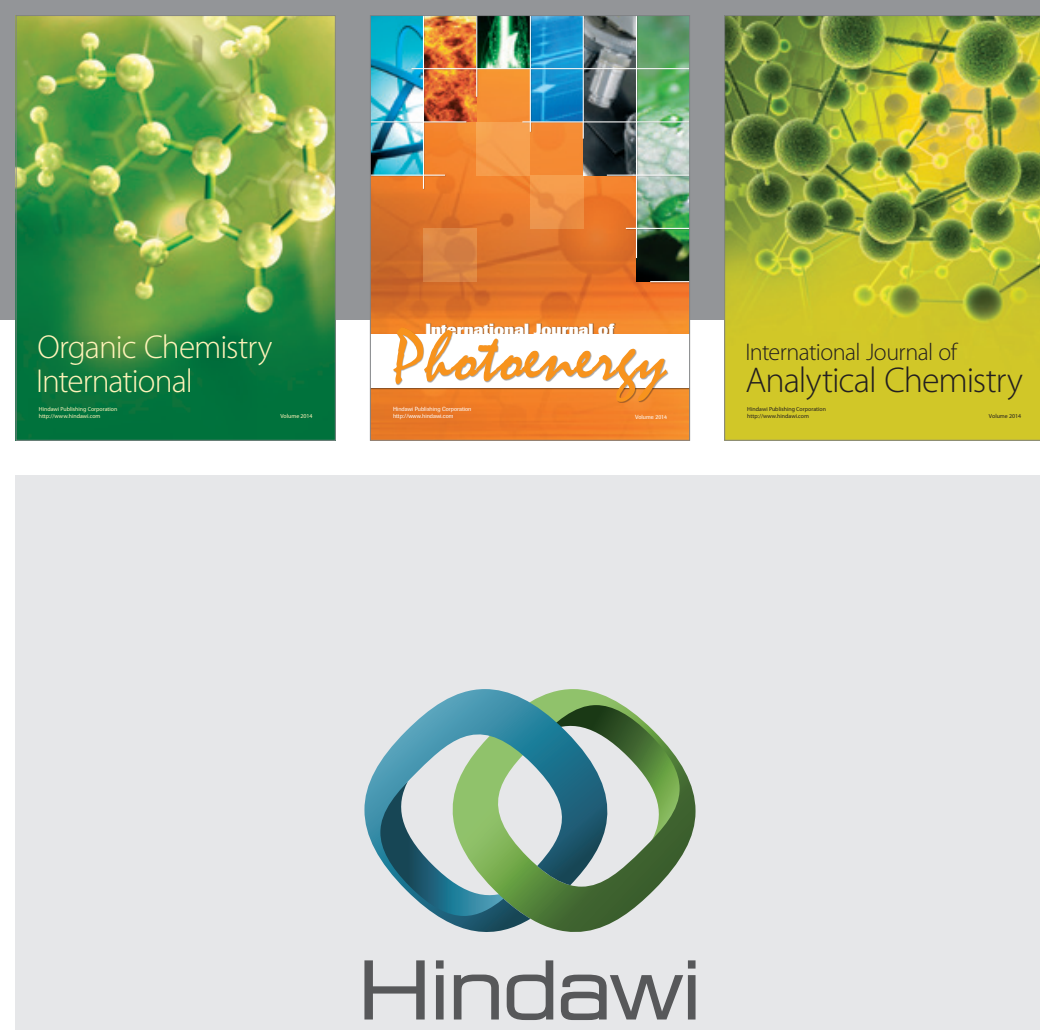

Submit your manuscripts at

http://www.hindawi.com
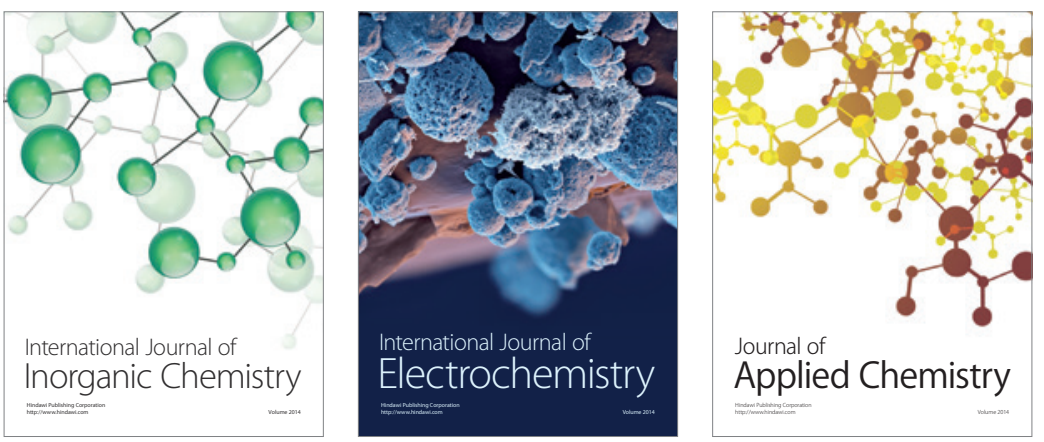

Journal of

Applied Chemistry
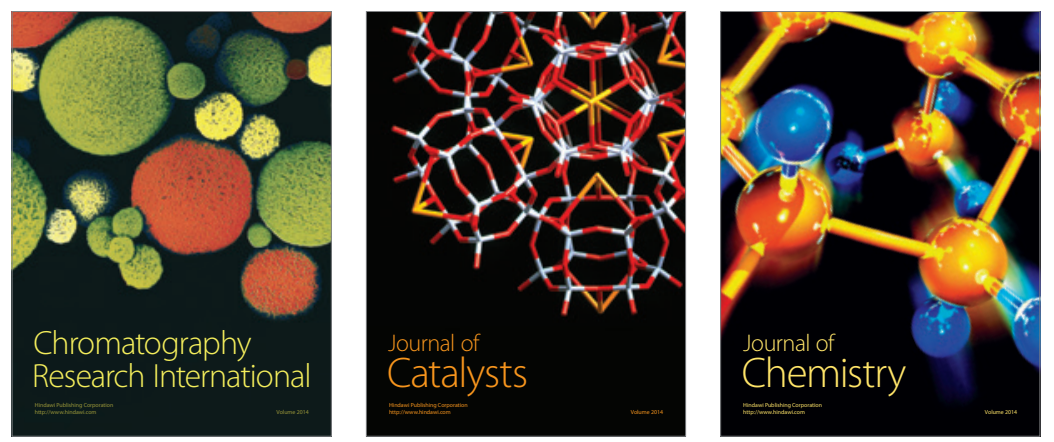
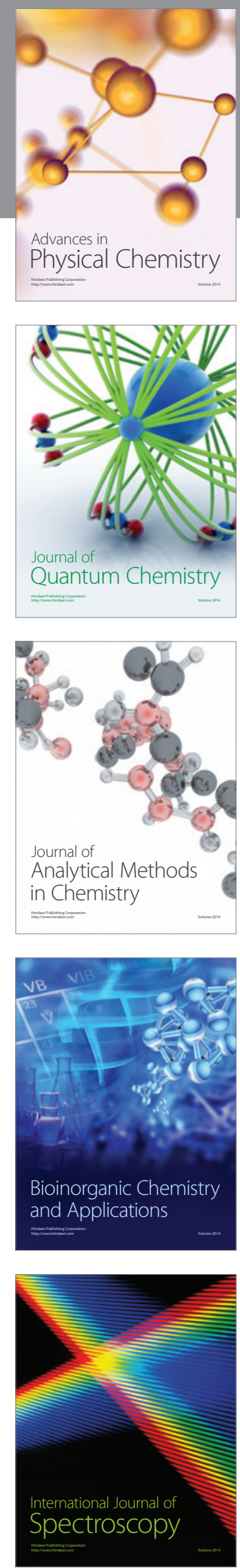